\title{
Design of New energy ship power safety monitoring system based on Internet of things
}

\author{
Yixue Wang ${ }^{1}$, Zhuoer Wang ${ }^{2, *}$, and Qiang Peng ${ }^{1}$ \\ ${ }^{1}$ School of Law, Humanities and Sociology, Wuhan University of Technology, Wuhan, China \\ ${ }^{2}$ School of Information Engineering, Wuhan University of Technology, Wuhan, China
}

\begin{abstract}
With the current technology of ship power battery and alternative fuel power system gradually mature, many countries have issued relevant policies to emphasize the promotion of ship new energy, while the current domestic ship related active safety system is still in the state of low automation, low intelligence and low integration. In this regard, the project introduces artificial intelligence algorithm to design a set of new energy ship power module monitoring system for fuel cell ships and pure electric ships, which can be used for marine power battery output management and safety monitoring, mainly including hydrogen fuel cell safety monitoring system, power battery (buffer cell) safety monitoring system and power integrated safety monitoring system. This work combines embedded technology with Internet of things technology and artificial intelligence algorithm to solve the safety management problem of new energy ship power system. If it is applied to the actual ship, obvious social and economic benefits can be achieved.
\end{abstract}

\section{INTRODUCTION}

At present, most of ships are powered by diesel fuel, which leads to excessive consumption of energy, resulting in a large number of emissions of pollutants. So the New energy ship are becoming the mainstream. But the construction of ship power safety management system has been an urgent problem to be solved. The causes of overheating of ship power system include electric short circuit, overcharge, rapid discharge, mechanical damage, manufacturing defects or poor design. Overheating will lead to "thermal runaway" reaction, and the exothermic reaction inside the battery will cause the temperature and pressure to rise rapidly. In order to avoid the above accidents, considering the inevitable development trend of new energy in the field of ship, this project takes the hybrid ship carrying fuel cell and power battery as the research object. By introducing artificial intelligence technology, multisensor fusion technology and embedded development technology, a power security monitoring system based on engineering standards is designed. The system has the functions of real-time monitoring of engine room environment, visualization of engine room information, multi-level alarm of abnormal conditions, etc., which can protect the safe operation of new energy power system.

\section{RELATED WORKS}

According to the action plan of energy technology revolution and innovation (2016-2030) jointly issued by the national development and Reform Commission and the National Energy Administration of China, the new energy of ship power system has become the general trend. However, due to various improper operations or reasons, lithium battery heat is out of control. If there is no pressure relief device inside the battery, it will explode as the internal reaction makes the internal pressure of the battery rise to a certain extent. Fire monitoring system has always been a research hotspot.

In 2018, Chen Xiao and others explored the configuration scheme of ship fire detector, and selected the special sensors for ships according to the standards of China Classification Society; in 2019, Ren Sailin and others built an intelligent distributed damage management monitoring system based on bilge water inflow monitoring and fire alarm; in 2020, Wei Lan and others built an embedded power battery Special fire monitoring system.

After the research is aimed at the new energy ships, continue to carry out the research of marine fire monitoring system, but most of them lack of intelligence and networking. So this project will propose a new energy ship monitoring system based on the Internet of things, which can clearly show the information in a visual way.

\section{OVERALL DESIGN}

The system uses the CAN Network On ship as the communication protocol, introduces the Internet of things technology, uses multi-level embedded system, multi-sensor and communication module to form the hardware system, introduces multi-sensor fusion algorithm and artificial intelligence control algorithm, which can extract and upload the current working status 
and safety information of the ship in real time, and automatically uses the status information to accurately determine the working status of each system Then, the battery management system based on artificial intelligence algorithm controls the safety input and output of the system. Finally, a stable, safe and efficient ship power system can be realized. And the system architecture is shown in Figure 1.

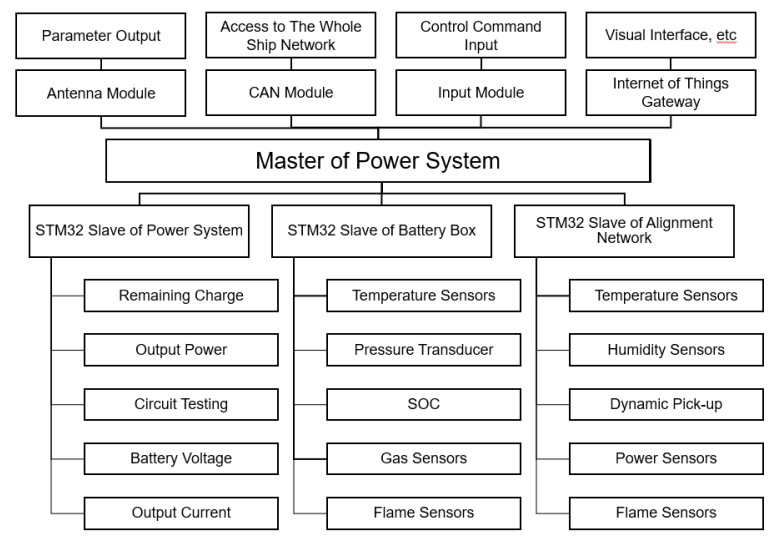

Fig. 1. Overall system architecture.

\subsection{Hardware design}

The processor of this system is divided into master control and slave control. The main control module takes STM32 industrial control board as the core, and the slave control module takes embedded STM32 minimum system as the core. Because the industrial control board has advanced CAN bus architecture, it can effectively meet the requirements of CAN communication. The master-slave processor adopts the architecture of edge cloud computing to build and allocate computing power.

\subsection{Electronic control system design}

In the aspect of data processing, taking the power battery as an example, the sensor system of the power battery monitors the real-time parameters and their change values of the fuel gas, smoke, temperature and flame detection points in the battery box through the coprocessor (low-level embedded processor), and uses the data monitoring model to dynamically process the parameter changes, so as to intelligently judge whether there is the risk of thermal runaway fire.

When the power battery breaks down and begins to release pressure and heat, the detector can detect abnormal changes, alarm and upload data at the early stage of the fire, realize hierarchical early warning and start the fire extinguishing device, and protect the power battery as much as possible. Leakage monitoring, flow monitoring and pressure monitoring sensors need to be added to the fuel cell, and the control algorithm needs to be improved. The sensor system architecture is shown in Figure 2.

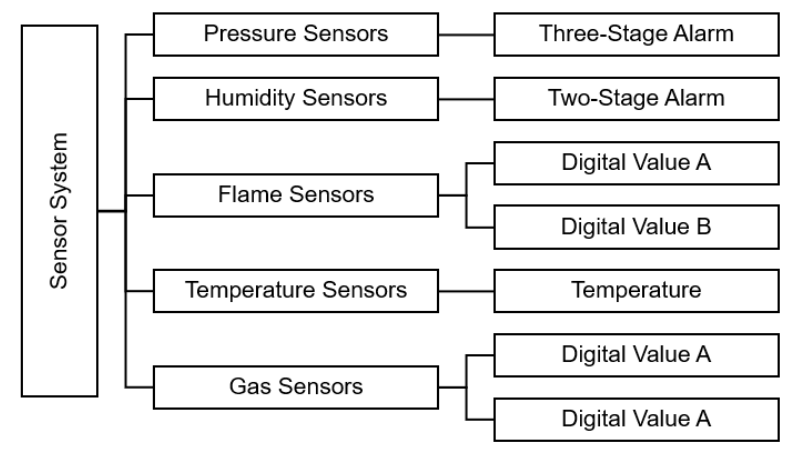

Fig. 2. Sensor system architecture schematic diagram.

In this system, the control system and the sensor system communicate through CAN bus. Because this design also needs to be connected to the CAN network of the ship, the relevant level and differential transmission circuit of the CAN module need to be compatible with the can network of the ship. In this design, the IO port of STM32 is connected to the CAN module.

There is a problem of baud rate matching in CAN controller. All devices on CAN bus must use the same baud rate. However, not all devices require the same master oscillator clock frequency. For devices with different clock frequencies, the baud rate should be adjusted by setting the frequency ratio.

The idea of the alarm part is to judge whether it meets the most advanced fault conditions according to the sensor data. If it exceeds and there is no treatment measures, judge whether the ship starts. If it is, start the screen display warning and alarm module of the operation console to realize the sound and light alarm, and actively start the fire protection system. The fuel cell department will immediately shut down the stack. If it is in the parking state, start the wireless module to transmit information to the command center and the person in charge of the ship, including the detailed identity information and longitude and latitude position information, and access to the fire protection system to take active measures to put out the fire; if the time from the last fault sending is less than 5 seconds or there is a command reply, the fault is determined to be eliminated, the alarm is stopped and the fault information is saved.

The system is mounted on the CAN bus of the ship to control the fire control system of the ship. At the same time, the CAN bus is also one of the channels to transmit information to the display screen (the standby channel is wireless communication). The protocol of mounting CAN bus has been encapsulated in the source code of STM32.

\subsection{Design of Visualization platform}

The platform selected in this paper provides data push function, which can take the platform as the client and send relevant information to the application server in the form of HTTP / HTTPS request. The relevant information includes:

1. Device new data point message.

2. Device up and down message. 
For the visualization platform, the simplicity and effectiveness of the display should be the focus, so the display part of the visualization platform needs to be processed. Therefore, this paper filters the data sent by the controller, takes the data stream template as the filtering condition, filters out a large number of time insensitive data such as frequent periodic reporting of the local controller, and only displays the data required by the ship's overall fault data and high real-time requirements.

In addition, the push function of the platform provides the function of data compression. Users can set the compression mode of data volume and time, and combine a certain amount of multi packet single information messages within a certain period of time into a JSON data containing multiple information, which can greatly reduce the processing pressure of the application server. Because there are many sensors in the power cabin, the amount of data is still large after the first filtering of each slave controller. This function can effectively save the bandwidth of the ship communication network.

\section{EXPERIMENT AND RESULT}

System testing not only requires functional testing of important functional modules, but also includes the stability and reliability testing of the whole system.

The important goal of the system testing project is targeted testing of the ship power battery fire monitoring system. The testing not only needs functional testing of the important functional modules, but also includes the stability and reliability testing of the overall system. The formal version also needs actual functional testing on the ship. It should focus on whether the system performance and function can meet the real expectations of the customers.

The test condition is to store the power cell cabin and fuel cell system on the ship in the simulated water area, and the fault simulation adopts three methods: short circuit, shutdown and artificial fault. The hydrogen energy stack used in this test is a sub unit of a $60 \mathrm{~kW}$ proton exchange membrane stack. The output characteristic curve of the system is consistent with that of the $60 \mathrm{~kW}$ stack, and the power is $60 \mathrm{~W}$.

The test indexes of each module of the specific system are shown in table 1 .

Table 1. System module test diagram.

\begin{tabular}{|c|c|}
\hline $\begin{array}{c}\text { Equipment } \\
\text { name }\end{array}$ & Quality Index \\
\hline $\begin{array}{c}\text { Communication } \\
\text { Module }\end{array}$ & $\begin{array}{c}\text { Signal strength, accuracy of } \\
\text { information. }\end{array}$ \\
\hline Control Module & $\begin{array}{c}\text { Five types of sensor information } \\
\text { detection and analysis, CAN } \\
\text { communication stability. }\end{array}$ \\
\hline Function Module & $\begin{array}{c}\text { The stability of wired / wireless } \\
\text { communication with control module } \\
\text { and the reliability of starting module. }\end{array}$ \\
\hline Display Module & $\begin{array}{c}\text { The screen is connected with the } \\
\text { serial port hardware of the control } \\
\text { system, and the response time of the }\end{array}$ \\
\hline
\end{tabular}

\begin{tabular}{|c|c|}
\hline & screen interface is improved. \\
\hline Sensor Module & $\begin{array}{c}\text { The continuity and independence of } \\
\text { environmental information } \\
\text { monitoring, and the stability of } \\
\text { connection with control module. }\end{array}$ \\
\hline
\end{tabular}

The test index of the function realization of the system is that each display and communication module is normal. The specific test index is shown in Table 2. Each function also needs to test the termination process after manual response, and the response time of each module should be less than 30 seconds.

Table 2. The specific test index.

\begin{tabular}{|c|l|}
\hline $\begin{array}{c}\text { Detection } \\
\text { performance }\end{array}$ & \multicolumn{1}{|c|}{ Test index } \\
\hline \multirow{2}{*}{$\begin{array}{c}\text { Information } \\
\text { upload }\end{array}$} & $\begin{array}{l}\text { After the control system confirms the } \\
\text { fault, it starts the wireless communication } \\
\text { module to send information to the } \\
\text { specified terminal according to the } \\
\text { specified data format to inform the current } \\
\text { fault type and the battery box number } \\
\text { where the fault is located. According to } \\
\text { the severity of the alarm level, the content } \\
\text { sent is different, and the information is } \\
\text { updated in real time according to the fault. }\end{array}$ \\
\hline $\begin{array}{c}\text { Wireless } \\
\text { sound and } \\
\text { light alarm }\end{array}$ & $\begin{array}{l}\text { When the CAN bus does not respond, the } \\
\text { wireless module starts and links the sound } \\
\text { and light alarm system on board to give an } \\
\text { alarm. }\end{array}$ \\
\hline $\begin{array}{c}\text { Whole ship } \\
\text { control access }\end{array}$ & $\begin{array}{l}\text { After the fault is confirmed by the control } \\
\text { system, the hull fire protection system is } \\
\text { linked through can to suppress the fire } \\
\text { actively. }\end{array}$ \\
\hline $\begin{array}{c}\text { Screen } \\
\text { display and } \\
\text { sound light } \\
\text { alarm }\end{array}$ & $\begin{array}{l}\text { The main control system can upload the } \\
\text { information, the visual platform displays } \\
\text { the specific information, and the sound } \\
\text { and light alarm system plays different } \\
\text { alarm information according to the } \\
\text { severity of the alarm level. }\end{array}$ \\
\hline
\end{tabular}

\subsection{Sensor and its control system test}

In order to facilitate the test, the system will process the parameters of each part of the sensor and output them from the slave controller. All the sensors work normally and the values meet the threshold. The test diagram is shown in Figure 3.

No flame detected
Hydrogen concentration not exceeding standard
Power Battery Temperature: $24.00^{\circ} \mathrm{C}$
Humidity of Power Battery(\%): 42
Internal Pressure of Power Battery: $101017 \mathrm{~Pa}$
Output Pressure of Power Battery: $12.50 \mathrm{~V}$
Normal Output Current of Power Battery
Output Power: $116.00 \mathrm{~W}$
Battery Remaining Capacity(\%): 20.50

Fig. 3. Overall system architecture. 
The test indexes of each module of the specific system are shown in table 3 .

Table 3. Sensor test table.

\begin{tabular}{|c|l|}
\hline Test function & \multicolumn{1}{|c|}{ Test content } \\
\hline Temperature & $\begin{array}{l}\text { After the temperature sensor module is } \\
\text { connected to the slave control system, it } \\
\text { can collect the temperature value of the } \\
\text { system more accurately and sensitively } \\
\text { by comparing with the handheld } \\
\text { electronic thermometer. }\end{array}$ \\
\hline Humidity & $\begin{array}{l}\text { Humidity acquisition is digital signal } \\
\text { output, spray water mist at 10cm } \\
\text { around humidity sensor, the sensor can } \\
\text { be triggered quickly, and the threshold } \\
\text { can be controlled. }\end{array}$ \\
\hline Pressure & $\begin{array}{l}\text { This test is compared with a pressure } \\
\text { gauge. Under a certain pressure, an } \\
\text { obvious signal can appear. }\end{array}$ \\
\hline \multirow{5}{*}{ Gas } & $\begin{array}{l}\text { During the test, ignite 10ml of battery } \\
\text { liquid and plastic mixture, and ignite at } \\
\text { 50cm away from the sensor. When there } \\
\text { is thick smoke in the rubber, the smoke } \\
\text { sensor must have information output. }\end{array}$ \\
\hline Flame & $\begin{array}{l}\text { During the test, the mixture of 10ml } \\
\text { battery liquid and plastic is ignited, and } \\
\text { ignited at 60cm away from the flame } \\
\text { sensor. During the ignition process, the } \\
\text { sensor is triggered, and the structure is } \\
\text { effective and sensitive. }\end{array}$ \\
\hline
\end{tabular}

The sensor output of the system is normal, there is no abnormal value, and the value refresh speed is normal. The sensor system passed the test.

\subsection{Visual platform testing}

The system visualization interface is divided into the distribution information area of Hull cell, the information area of monthly alarm number, the statistical information area of the cabin power consumption, the environment information area of fuel cell and power cell cabin, the information area of kinetic energy output power and the information area of the energy storage of fuel and battery. All data are updated in real time with the data collected by the sensor. The visualization platform interface is shown in Figure 4.

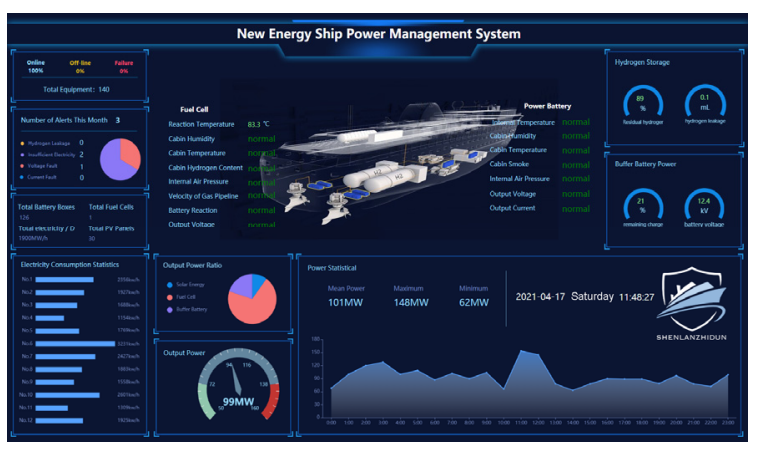

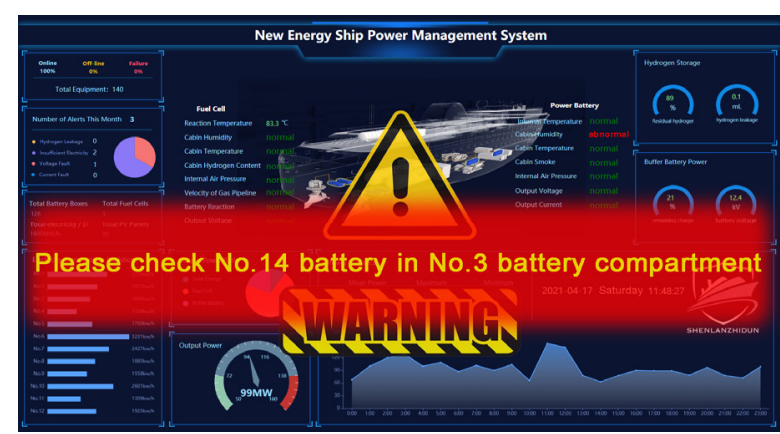

Fig. 4. Visualization platform display.

It can be seen from the figure that the alarm function and display function of the visualization platform are normal, and the relevant intelligent alarm system is in good working condition. This device has the basis of marine engineering, and the test is successful.

\section{CONCLUSION}

This design can effectively ensure the safe charging of the ship power battery and the safe output of the power system. In terms of hardware, the actual needs of the ship are fully considered in the design, the supplementary selection of sensors is made according to the characteristics of the power system, the multi-sensor is configured according to the specific ship power battery box, and the master-slave sensor filtering mechanism is introduced according to the relevant safety indicators of the ship, so as to reduce the false alarm rate as much as possible. The visualization platform based on the Internet of things makes the data clear at a glance, which effectively ensures the security of the joint system and the realizability of simulation parameters.

\section{References}

1. Qin Qi and Wang Youzhen, "Global New Energy (C lean) Ships and Related Intelligent Technology Dev elopment," Ships, 29, 29-41 (2018)

2. Fan Wei, Wang Jing and Feng Shuhuan, "Developm ent of Marine Battery Power Technology," China Sh ipbuilding Survey, 66-69 (2020)

3. TORAL S L, BARRERO F, CORTÉS F, et al. Anal ysis of Embedded CORBA Middleware Performanc e on Urban Distributed Transportation Equipments. Computer Standards \& Interfaces, 35, 150-157 (201 3)

4. Yu Quanhu, "Analysis on the Development of Powe r Lithium Batteries and Electric Propulsion Ships," Transportation Energy Conservation and Environme ntal Protection, 16, 29-35 (2020)

5. Design and implementation of ship integrated navig ation system based on Embedded Linux. Chen Lijia, Wang Yibing, Wang Jie. Ship engineering. 03 (201 4)

6. Research on similarity of flue gas temperature distri bution in different scale shaft models based on CFD 
simulation. Zhang Qiang, Jiang Yong, Qiu Rong, X u Li, ran Nan. Fire science. 01 (2016) 